\title{
Prayer and Religion-Irish Nurses Caring for an Intellectually Disabled Child Who Has Died
}

\author{
Paul Michael Keenan ${ }^{1}$ and Ciara MacDermott ${ }^{2, *}$ \\ 1 School of Nursing and Midwifery, Trinity College Dublin, The University of Dublin, College Green, \\ Dublin 2, Ireland; paul.keenan@tcd.ie \\ 2 St. Michael's House, Adare Green, Coolock, Dublin 5, Ireland \\ * Correspondence: ciaramacdermott.nurse.emt@gmail.com
}

Academic Editors: Fiona Timmins and Wilfred McSherry

Received: 30 November 2016; Accepted: 10 December 2016; Published: 15 December 2016

\begin{abstract}
This research paper was presented at the Second International Spirituality in Healthcare Conference 2016-Nurturing the Spirit held at Trinity College Dublin, The University of Dublin. 23rd June 2016. Historically, nursing has had a sound "spiritual" grounding. However, some contemporary health literature is questioning spirituality's relevance, and practitioners often shy away from it. This article aims to highlight the findings of a study which, in exploring the nurse's personal grief relating to caring for a child with an intellectual disability who has died, identified the practice and value of spirituality in nursing practice. A qualitative descriptive research approach was employed. Semi-structured interviews were undertaken with eight female nurses who had cared for a child with an intellectual disability who has died. Data was analyzed using Newell and Burnard's pragmatic approach to qualitative data. Ethical Approval was granted by University of Dublin, Trinity College and the relevant healthcare provider. Eight broad themes emerged from the study. "Prayer and Religion" was a sub-theme of "Focusing on the positive", which is the main focus of this article, and discussed in depth for the first time. Spirituality and religion plays a key role in the daily lives of many nurses, who further embrace this aspect of their lives when managing dying, death and bereavement. It became evident that spirituality was not merely a reactive strategy, but one underpinning a participant's core nursing values. Nurse Managers and colleagues should continue to acknowledge, respect and support staff's spirituality.
\end{abstract}

Keywords: grief; nursing; children; intellectual disabilities; support; spirituality; religion; faith; qualitative research; semi-structured interviews

\section{Introduction}

This paper was presented at the Second International Spirituality in Healthcare Conference 2016-Nurturing the Spirit held at Trinity College Dublin, The University of Dublin, 23rd June 2016.

Paediatric palliative care is an area of practice where nurses encounter grief. In this rapidly developing area of nursing, it is important that the care of the professional is considered simultaneously with the care of the children and families [1-3]. Nurses receive their support in different ways from varying sources. One area of support is the nurse's own and colleagues' spirituality $[4,5]$.

This paper focuses on the sub-theme of prayer and religion, which was identified in a qualitative descriptive study into the grief experience of eight female nurses who have cared for children with an intellectual disability who have died.

\section{Literature Review}

The literature review searched the following professionally respected databases: Cumulative Index to Nursing and Allied Health Literature (CINAHL), Pubmed, Cochrane, Medline, and 
Internurse.com to uncover from the most reliable peer-reviewed literature what is currently known and not known in this area of nursing practice. The search terms and their equivalents were "grief", "nurse", "nurse's role", "grief experience", "death", "intellectual disability", "palliative care" and "children", "support".

According to the Irish Scope of Nursing and Midwifery Practice Framework, in practicing the art and science of nursing holistically, professional practice should be "grounded in an understanding of the social, emotional, cultural, spiritual, psychological and physical experiences of patients ... " [6]. While the nursing literature provides a varied range of definitions for spirituality, no one authoritative definition is evident [7], and the term is not very well understood within practice [8]. However, Narayanasamy [9] states that it is basically an individual's search to seek meaning in life. Walsh ([10], p. 158), in discussing Lumen Fidei [11], offers further depth to this in that he speaks of spirituality in terms of giving "meaning and purpose to our lives". The concept "religion" is seen as interconnected, yet separate to "spirituality" and can be understood as the practice by individuals of particular theological beliefs and values through ritualistic frameworks $[7,12]$ and everyday living.

Nurses practice in an increasingly secular age, where many nurses shy away from identifying the spiritual needs of others [7], and, therefore, do not adequately respond. This may raise ethical concerns regarding, for example, omission. Equally, a study by Shinbara and Olsen [13] explored spirituality that relates to nurses grieving for the loss of patients. This study highlights that spirituality is described as a support that nurses use and find effective. Seventy-five percent of the research participants in their study reported that spirituality was important in their daily lives, while seventy percent said that spirituality supported them in coping with the grief associated with patient loss. Holland and Niemeyer [14] discussed the everyday experiences of spirituality relating to professional well-being, specifically related to the effect on burnout levels and staff resilience. MacDonald and Friedman [15] suggest that higher levels of spirituality correlate to a lower level of burnout in nurses.

No research studies were retrieved that focused on the nurse's grief experience when caring for a child with an intellectual disability who has died, thus providing justification for undertaking the study in the first place.

\section{Aim and Objectives}

The aim of the study was to explore the individual grief experience of nurses who have cared for a child with an intellectual disability who has died. The purpose was to increase professional knowledge in this area with a view to improving nursing practice. The study's objectives were to ascertain the nurses' understanding of grief, to gain an understanding of the nurses' personal grief experiences, and to establish the support systems nurses utilise to manage personal grief, and evaluate their effectiveness.

\section{Methodology}

Research Design: A qualitative descriptive research approach was used. This provided participants with the opportunity to describe their grief experience and how this was managed. This provided an opportunity to gain a deeper understanding of the personal grief experiences of these nurses, and how this may be comparable to other nurses in similar situations.

Ethical Considerations: Ethical Approval was granted by Trinity College Dublin and the relevant healthcare organisation.

Setting: The research study was undertaken in an Irish healthcare organisation for people with an intellectual disability. The interviews were conducted in a private room in the nurse's workplace: respite, residential or school settings.

Recruitment and Participants: Participation in this study was open to all nurse specialisms (i.e., general, intellectual disability, psychiatric, paediatric, and midwives), provided they were registered with the Nursing Board. Purposive sampling was used to recruit participants, who were all recruited from one intellectual disability organisation. Eight registered nurses were selected to partake in the 
study. These met the inclusion criteria, which included being registered nurses who have worked with a child who has an intellectual disability who has died within the last seven years. Nurses who did not meet this criteria were excluded. This particular timeframe was chosen to ensure the study was open to a large number of nurses. It was felt that a period greater than seven years would not be appropriate, as there may be bias in recall. Other healthcare professionals were also excluded from the study.

The distribution of Participant Information leaflets, Participant Consent forms, and letters inviting nurses to participate in the study was facilitated by a gatekeeper from the organisation. All participants were female, ranging in age from 20 to 65 years of age, with five to 40 years nursing experience. Five were on the live nursing register as Intellectual Disability Nurses and three as General Nurses. While each of the nurses in the study had experienced multiple deaths, none of the nurses reported to have had received training in bereavement.

Data Collection: Semi-structured interviews were conducted using an interview schedule informed by the literature review and the study aims. This allowed the researcher to gather the required data, and enable the participant the freedom to disclose what they felt necessary. Interviews each lasted approximately one hour. Interview data was recorded using a sound-recording device, and transcribed verbatim by the researcher. Participants provided written consent to the interview process prior to the interview, and again verbally on the day of the interview.

\section{Data Analysis}

A pragmatic approach to qualitative data analysis [16] was used to analyse the data obtained through the semi-structured interviews. This involved the researcher reading the transcripts of the interviews, and noting any general themes that emerged from the data. Several of the themes were anticipated, such as grief and relationship with the child, but other themes also emerged such as "focusing on the positive" with the sub-theme of prayer/religion. The subject of spirituality had not been anticipated by the researcher. After the re-reading of the transcripts, 24 open coding headings were generated which covered all aspects of the data from each of the eight transcripts. The number of codes was then reduced to eight key themes and their relevant sub-themes using higher order headings. The eight themes were: Grief; Relationship with the child; End of life; Support; Helplessness due to limited experience and knowledge; The family; The funeral and; Focusing on the positive (see [2], p. 587; [4,5]).

\section{Finding}

Under the theme "Focusing on the positive", prayer and religion was identified as a sub-theme. During the interview process, six of the eight nurse participants made reference to God and prayer. Participants perceived religion as an integral part of their everyday meaning, life and practice. The nurses demonstrated a faith which was constant, but also from which they obtained their strength during the dying and death of the child, and after the child's death. Their faith was not solely important during their experiences of grief, but it augmented their nursing practice. For example:

"God called her that day and she chose to go to him." (Participant 2)

"I know he's in heaven-he's one of God's angels now." (Participant 5)

"He was sleeping like one of God's angels." (Participant 7)

"I knew that he would be in a better place in the arms of God." (Participant 6)

"I pray for her." (Participant 2)

\section{Discussion}

The findings reported in this paper support Shinbara and Olsen's [13] conclusions that nurses do use spirituality within the context of professional support. Many nurses also use some form of religious resource to help cope with the death of a patient, etc. [17-19]. Furthermore, MacDonald and Friedman [15] argue that higher levels of spirituality correlate to a lower level of burnout in nurses. This suggests that spirituality enhances mental well-being and quality of nursing care. 
We found that $80 \%$ of the nurses interviewed in our study made reference to God and demonstrated that their faith was consistent, and not simply drawn upon at times of difficulty. Our research illustrates that the spiritual care of self and others are considered by some nurses as a core component of nursing care within the context of management of self and colleague support. Our study demonstrates that nurses utilise their spirituality to make sense of and frame their service, the death of the child, to manage the grief they are experiencing and to provide caring support to their colleagues.

However, this is not the case for all nurses. Nurses working within Ireland grew up in a culture where religion was central throughout their education and, in many cases, working lives. However, within the contemporary work environment, the emphasis on spiritual/religious practice has been changing and nurses drawing on their own spiritual resources, as well as meeting the spiritual needs of patients within a holistic framework, appear unclear. Practice operates within a continuum [7]. It can be argued that this continuum has over-assertive/corrosive secularism/agnosticism/atheism on the one end and pushy proselytism on the other. Although, in reality, most nurses probably operate somewhere in the middle.

In terms of implementations for practice, nursing bodies, such as the Royal College of Nursing $(\mathrm{RCN})$ and their Irish counterpart, the Nursing and Midwifery Board of Ireland (NMBI), provide some guidance or make reference to nurses and midwives supporting patients' spirituality, but could extend this to include the spiritual care of staff. Our findings reinforce the fact that many nurses find spirituality effective and supportive. In addition, they offer Nurse managers and staff a mandate to provide proactive and effective support mechanisms for staff through education so that nurses understand the influence and impact of religion on peers-in addition, through, for example, creating a space which respects, understands and enables spirituality so that their peers are not spiritually vulnerable, at risk, or unsafe when providing care to patients and receiving support from peers.

The authors hope to undertake further research that examines, for example, the extent to which nurses feel willing and able to respond to the spiritual needs of colleagues and what effective supports they require.

\section{Limitations}

As is the nature of a small-scale qualitative study, the findings may not be generalized and are also context-dependent in terms of being undertaken in one country: Ireland and within one Health Service Provider. In addition, all of the participants happened to practice the same religion.

\section{Conclusions}

We practice in an increasingly secular age where space is not always created to acknowledge, respect or promote the practice of spirituality and religion. Spirituality plays a central role in the professional lives of many nurses. These nurses further embrace this aspect of their lives if difficulties arise, such as dying, death and bereavement. It was evident that spirituality was not simply a reactive strategy in a time of need, but one of deep meaning and value to the nurses and was embedded within their holistic nursing care.

Acknowledgments: Financial support: The Queen's Institute of District Nurses in Ireland and the Irish Hospice Foundation.

Author Contributions: Ciara MacDermott conceived, wrote and implemented the research study protocol. Paul Michael Keenan provided research supervision to Ciara MacDermott throughout the whole research process. Paul Michael Keenan conceived the paper. Ciara MacDermott and Paul Michael Keenan jointly developed the intellectual content of the article. Paul Michael Keenan reviewed, finalized and edited the full paper.

Conflicts of Interest: The authors declare no conflict of interest. 


\section{Abbreviations}

The following abbreviations are used in this manuscript:

NMBI National Nursing and Midwifery Board of Ireland (NMBI)

RCN Royal College of Nursing (UK)

\section{References}

1. Paul Michael Keenan, and Paul McIntosh. "Learning Disabilities and Palliative Care-Professional Development Need." Palliative Care Today 9 (2000): 11-13.

2. Ciara MacDermott, and Paul Michael Keenan. "Grief experiences of nurses in Ireland who have cared for children with an intellectual disability who have died." International Journal of Palliative Nursing 20 (2014): 584-90. [CrossRef] [PubMed]

3. Ciara MacDermott, and Paul Michael Keenan. "The nurses' grief- having cared for a child with an intellectual disability who has died." In Proceeding of the 15th Healthcare Interdisciplinary Research Conference, School of Nursing and Midwifery, Trinity College Dublin, The University of Dublin, Dublin, Ireland, 4-6 November 2014.

4. Paul Michael Keenan, and Ciara MacDermott. "How nurses grieve for children who die in their care." Learning Disability Practice 19 (2016): 16-22. [CrossRef]

5. Paul Michael Keenan, and Ciara MacDermott. "Spirituality and Grief-The nurse's experience in caring for children with an Intellectual Disability who have died in their care." Invited talk to The Spirituality Interest Group, School of Nursing and Midwifery, Trinity College Dublin, The University of Dublin, Dublin, Ireland. 5 May 2016.

6. NMBI. "Scope of nursing and midwifery practice framework." 2015. Available online: http://www.nmbi.ie/ Standards-Guidance/Scope-of-Practice (accessed on 24 November 2016).

7. Fiona Timmins, and Wilfred McSherry. "Editorial—Spirituality: The Holy Grail of contemporary nursing practice." Journal of Nursing Management 20 (2012): 951-57. [CrossRef] [PubMed]

8. Fiona Timmins, Maryanne Murphy, Sílvia Caldeira, Eimear Ging, Carole King, Vivienne Brady, Jacqueline Whelan, Colm O’Boyle, John Kelly, Freda Neill, and et al. “Developing Agreed and Accepted Understandings of Spirituality and Spiritual Care Concepts among Members of an Innovative Spirituality Interest Group in the Republic of Ireland." Religions 7 (2016): 30. [CrossRef]

9. Aru Narayanasamy. "The puzzle of spirituality: A guide to practical assessment." British Journal of Nursing 13 (2004): 1140-45. [CrossRef] [PubMed]

10. William Walsh. No Crusader. Dublin: The Columba Press, 2016.

11. Pope Franciscus. Lumen Fidei. Vatican: Vatican Library Editions, 2013. Available online: http://w2.vatican.va/content/dam/francesco/pdf/encyclicals/documents/papa-francesco_20130629_ enciclica-lumen-fidei_en.pdf (accessed on 24 November 2016).

12. Loralee Sessanna, Deborah Finnell, and MaryAnn Jezewski. "Spirituality in Nursing and Health-Related Literature." Journal of Holistic Nursing 25 (2007): 252-62. [CrossRef] [PubMed]

13. Christina G. Shinbara, and Lynn Olsen. "When nurses grieve: Spirituality's role in coping." Journal of Christian Nursing 27 (2010): 32-37. [CrossRef] [PubMed]

14. Jason Holland, and Robert A. Neimeyer. "Reducing the risk of burnout in end-of-life care settings: The role of daily spiritual experiences and training." Palliative and Supportive Care 3 (2005): 173-81. [CrossRef] [PubMed]

15. Douglas MacDonald, and Harris Friedman. "Assessment of humanistic, transpersonal and spiritual constructs: State of the science." Journal of Humanistic Psychology 42 (2002): 102-25. [CrossRef]

16. Robert Newell, and Philip Burnard. Research for Evidence-Based Practice in Healthcare. London: John Wiley \& Sons, 2011.

17. Charles S. Carver, Michael F. Scheier, and Jagdish K. Weintraub. "Assessing Coping Strategies: A theoretically based approach." Journal of Social Psychology 56 (1989): 267-83. [CrossRef]

18. Susan Phelps, and Patricia Jarvis. "Coping in adolescence: Empirical evidence for a theoretically based approach to assessing coping." Journal of Youth and Adolescence 23 (1994): 359-71. [CrossRef] 
19. Jennifer Peterson, Malynnda Johnson, Bonnie Halvorsen, Lisa Apmann, Pi-Ching Chang, Stephanie Kershek, Courtney Scherr, Matthew Ogi, and Deborah Pincon. "Where do nurses go for help? A qualitative study of coping with death and dying." International Journal of Palliative Nursing 16 (2010): 432-38. [CrossRef] [PubMed]

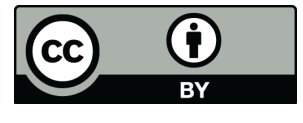

(C) 2016 by the authors; licensee MDPI, Basel, Switzerland. This article is an open access article distributed under the terms and conditions of the Creative Commons Attribution (CC-BY) license (http:/ / creativecommons.org/licenses/by/4.0/). 